\title{
Recurrent Mesenteric Fibromatosis - A Case Report
}

\author{
Tejas A P ${ }^{1}$, Revanasiddappanadgir ${ }^{2}$, Harish Kumar ${ }^{3}$ \\ ${ }^{1}$ Junior resident, Department of general surgery, Raja Rajeswari Medical College and Hospital, Bangalore, Karanataka, India \\ ${ }^{2}$ Professor, Department of general surgery, Raja Rajeswari Medical College and Hospital, Bangalore, Karanataka, India \\ ${ }^{3}$ Assitant Professor, Department of general surgery, Raja Rajeswari Medical College and Hospital, Bangalore, Karanataka, India
}

\begin{abstract}
Mesenteric fibromatosis is a part of the clinical-pathologic spectrum of deep fibromatoses. The deep fibromatoses encompass a group of benign fibroproliferative processes that are locally aggressive and have the capacity to infiltrate or recur but not metastasize. Here we present a case of recurrent mesenteric fibromatosis in a 18 year old male patient. The Diagnosis is based on the histopathological examination of the tumor.
\end{abstract}

Keywords: Mesenteric Firomatosis, Gardner's Syndrome, Desmoid Tumor, Previous Abdominal Surgery, Enbloc Resection of the Tumor, Beta-Catenin Expression

\section{Introduction}

Mesenteric fibromatosis (MF) is a locally aggressive myofibroblastic proliferation of the mesentery.It is characterized by a spatially homogeneous proliferation of wavy spindle cells without atypia, associated with collagen deposition (often of the keloidal type), and an infiltrative border.

Mesenteric fibromatosis occurs in a wide age range of patients with 14-75 years of age In contrast, abdominal fibromatosis occurs most commonly in young women, 2030 years of age. $13 \%$ of pateints with mesenteric fibromatosis have gardner's syndrome variant of Familial adenomatous polyposis.

\section{Case Report}

A 18 year old boy presented with complaints of mass abdomen and bilateral swelling of both the lower limbs since 2 years. Initially the swelling started as incidious in onset gradually progressive in nature to the present size, dull aching in nature, radiating to the back and lower limbs.

- Patient gives history of previous abdominal surgery for the similar complaints 3 years back.

- No history of fever/vomiting/altered bowel habits/burning micturion/ decreased urine output/jaundice.

- Patient had no comorbid conditons like diabetes, hyperstension, asthma.

- On examination, patient had pallor and bilateral swelling of the lower limbs.

On inspection of the abdomen there was a lower midline laparotomy scar of the previous surgery and a Swelling was noticed in the abdomen was located in the epigastric, Left hypochondriac and hypogastric region measuring $15 * 10 \mathrm{cms}$ not ballotable non pulsatile firm in consistency irregular surface and all borders are well made out and does not move with respiration and does not fall forward in knee chest position and dull to percuss and bowel sounds were heard. Hernialorifices and external genitalie were found to be normal. Digital rectal examination was found to be unremarkable. Other systems were normal.

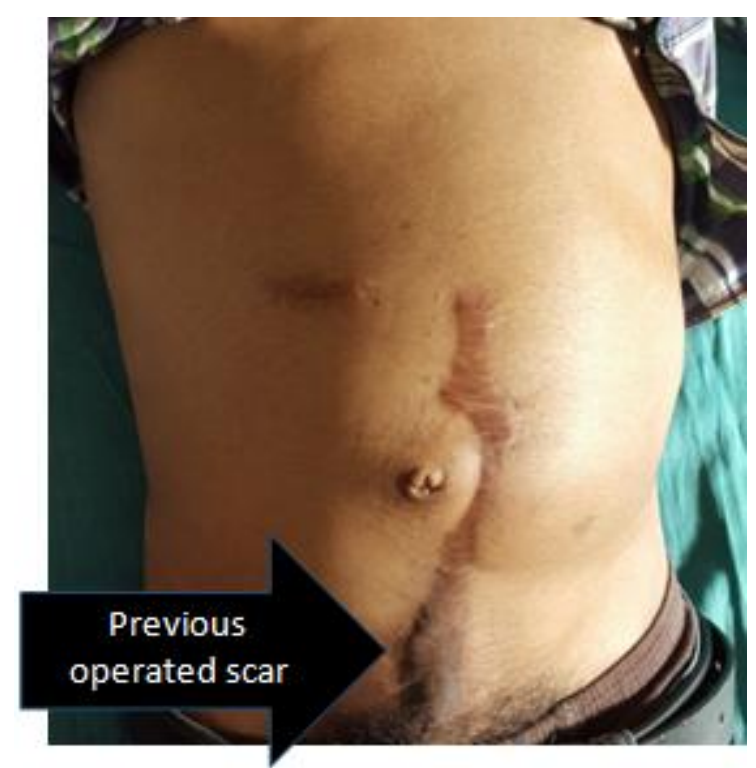

Figure 1: Pre operative picture showing the mass in the abdomen and previous surgical scar

Patient was evaluated with working diagnosis of retroperitoneal tumour.

Patient was thoroughly investigated and all routine baseline investigations were found to be normal. Erect xray abdomen was normal.

CECT abdomen and pelvis was done as shown in the Fig 2and fig 3 shows the following changes:

Large lobulated moderately enhancing soft tissue density mass lesion measuring $22 * 16 * 12 \mathrm{~cm}$ in the abdomen and pelvis and retroperitoneal region encasing both mid ureters, sigmoid colon and few small bowel loops with bilateral moderate hydroureteronephrosis.

Colonoscopy was normal and Intravenous pyeolography was normal. With the above CECT showed features suggestive of desmoid tumor. 


\section{International Journal of Science and Research (IJSR) \\ ISSN (Online): 2319-7064}

Index Copernicus Value (2013): 6.14 | Impact Factor (2014): 5.611

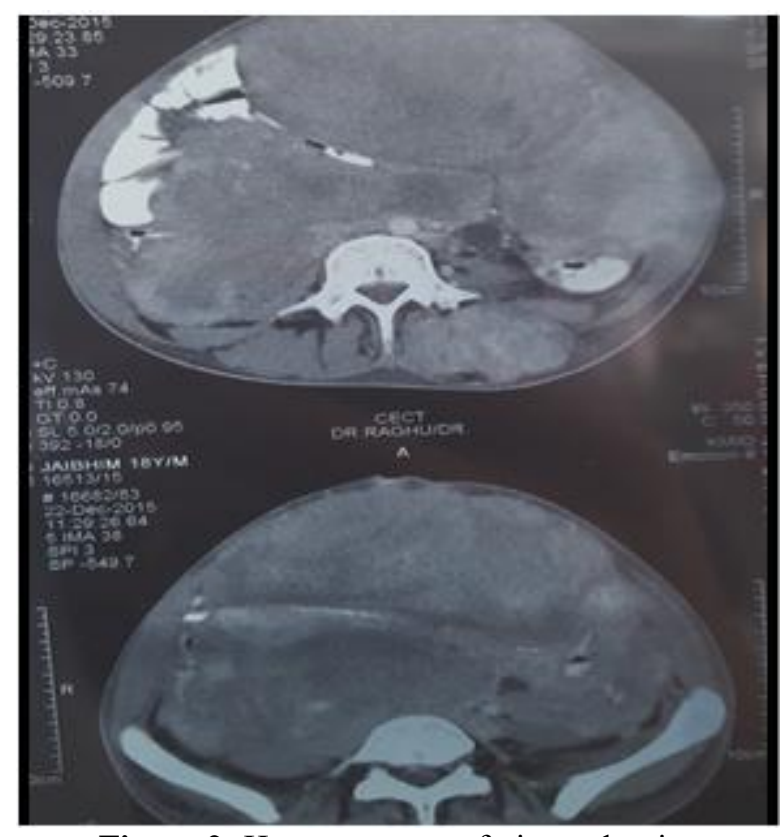

Figure 2: Heterogenous soft tissue density

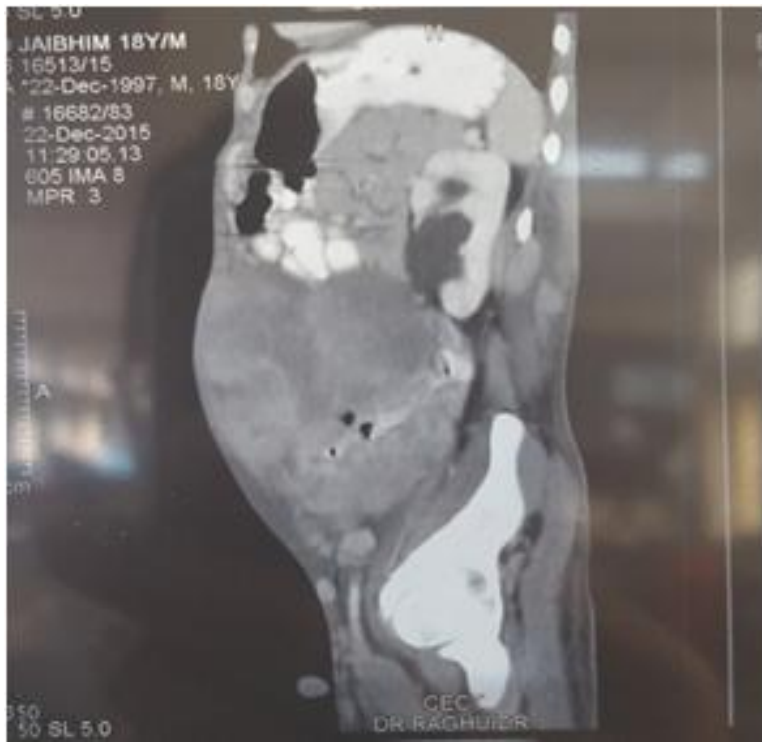

Figure 3: Heterogenous soft tissue density sagittal view

Patient underwent exploratorylapratomy with intestinal resection and anastamosis under general anesthesia and Fig 4 showing the intra operative photograph of the tumor adherent to the sigmoid colon and small intestine and Fig 5 demonstrating resected tumor with part of the bowel weighting $4.2 \mathrm{kgs}$.
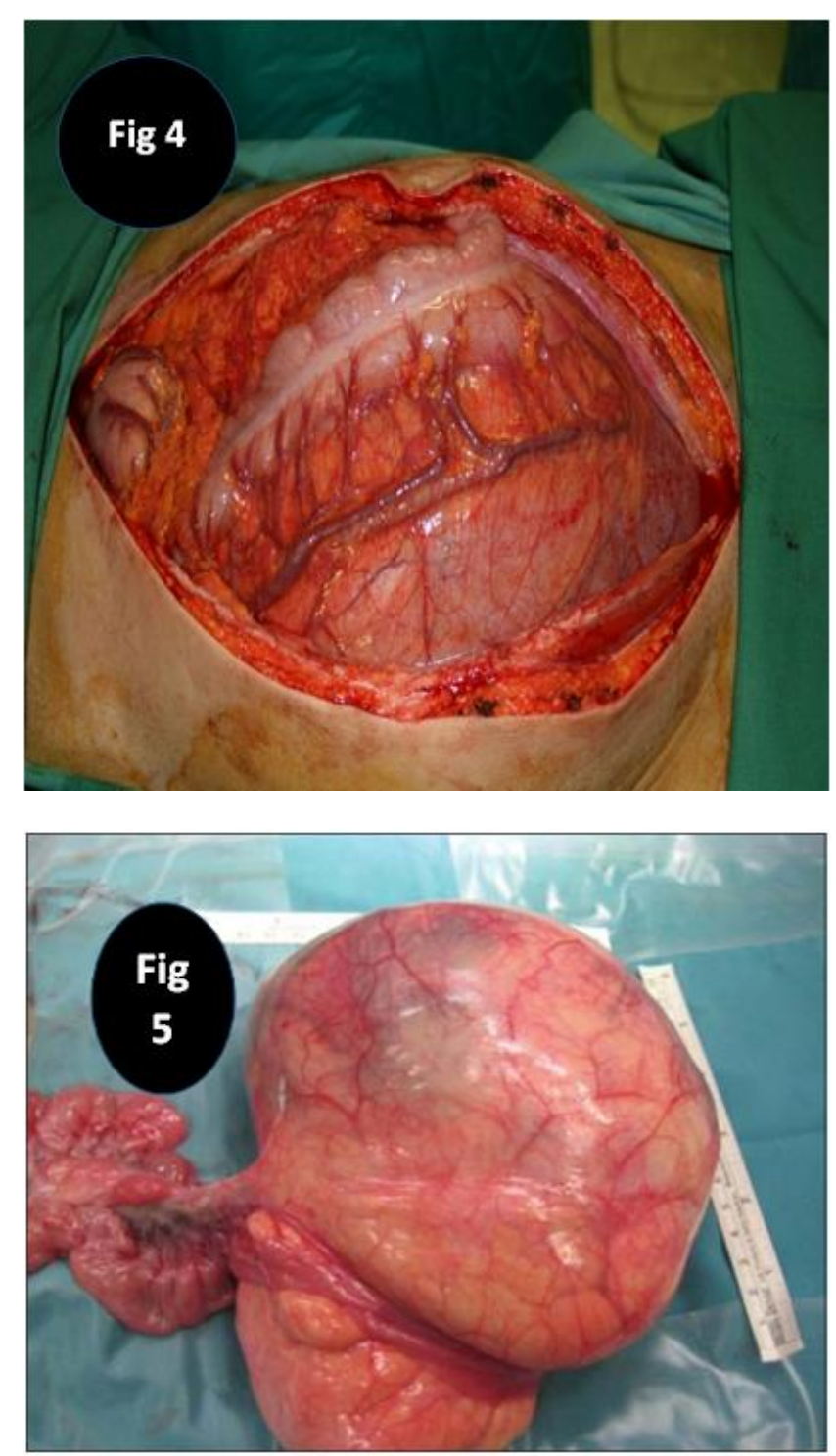

Resected tumor was sent for histopathological examination and demonstrated as shown in Fig 6. Sprinckling of mononuclear cells and compressed thin walled vessels with plump endothelial cells and perivascular lymphocytic infiltrates. Features suggestive of desmoid fibromatosis.

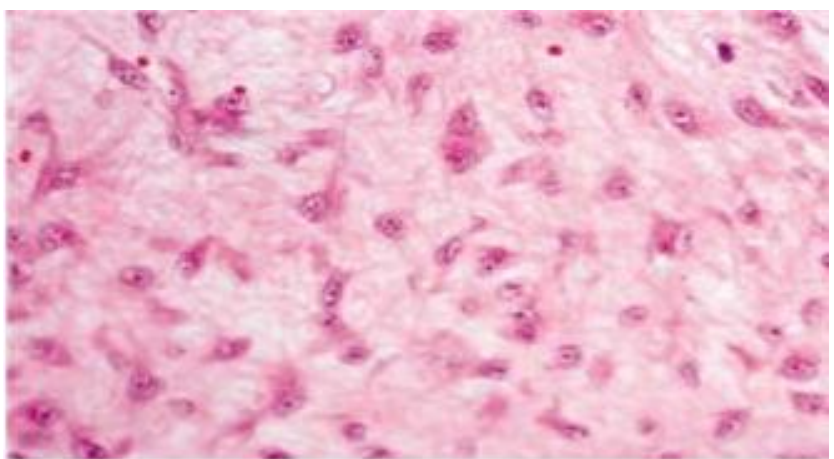

Figure 6: High-power view of a field displaying cytologic characteristics of MF, with stellate fibroblasts, plump nuclei, and micronucleoli.

Immunohistochemistry was done and spindle cells expressed beta-catenin as shown in Figure 7. 


\section{International Journal of Science and Research (IJSR) \\ ISSN (Online): 2319-7064}

Index Copernicus Value (2013): 6.14 | Impact Factor (2014): 5.611

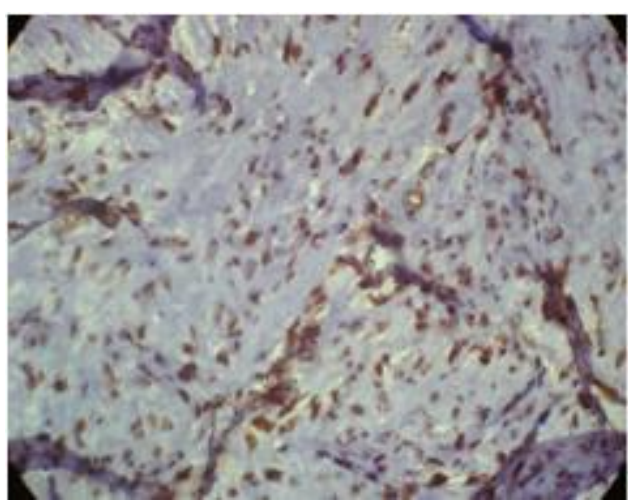

Figure 7: Positive for beta-catenin.

\section{Discussion}

Mesenteric fibromatosis is a type of fibroblastic proliferation affecting the mesentery that develops usually as a consequence of surgical trauma or occur spontaneously.

Imaging remains the mainstay of preoperative investigations to diagnose mesenteric fibromatosis.

The sonographic features of mesenteric fibromatosis are nonspecific and chiefly dependent on collagen and fibroblast content and intra-lesional vascularity of the tumor [1].

CT scan is considered the first-line imaging modality for identifying, characterizing, and staging fibromatosis.[2]

Microscopically, mesenteric fibromatosis is characterized by a spatially homogenous proliferation of wavy spindle cells without atypia, associated with collagen among dilated vessels. The mitotic count is relatively low with no evidence of necrosis and nuclear dedifferentiation [3].

MF does not express CD34 and S100 protein. Recently, the expression of beta-catenin was revealed in fibromatoses that might prove helpful

Wide field surgical excision is the first-line treatment for most mesenteric fibromatosis [4]

Adjuvant radiation therapy reduces recurrence of mesenteric fibromatosis to $20 \%-40 \%$, compared to $40 \%-$ $70 \%$ with resection only [5].

\section{Reference}

[1] G. Guglielmi, A. Cifaratti, G. Scalzo, and N. Magarelli, "Imaging of superficial and deep fibromatosis,"RadiologiaMedica, vol. 114, no. 8, pp. 1292-1307, 2009. View at Publisher · View at Google Scholar $\cdot$ View at Scopus

[2] A. P. Brooks, R. H. Reznek, K. Nugent, K. C. R. Farmer, J. P. S. Thomson, and R. K. S. Phillips, "CT appearances of desmoidtumours in familial adenomatous polyposis: further observations, " Clinical Radiology, vol. 49, no. 9, pp. 601-607, 1994. View at Google Scholar · View at Scopus
[3] J. A. Rodriguez, L. A. Guarda, and J. Rosai, "Mesenteric fibromatosis with involvement of the gastrointestinal tract. A GIST simulator: a study of 25 cases," The American Journal of Clinical Pathology, vol. 121, no. 1, pp. 93-98, 2004. View at Publisher · View at Google Scholar · View at Scopus

[4] C. H. Yang, S. M. Sheen-Chen, C. C. Lu, S. F. Ko, and H. L. Eng, "Computed tomographic presentation of mesenteric fibromatosis, "Digestive Diseases and Sciences, vol. 50, no. 2, pp. 348-350, 2005. View at Publisher - View at Google Scholar - View at Scopus.

[5] J. Khorsand and C. P. Karakousis, "Desmoid tumors and their management," The American Journal of Surgery, vol. 149, no. 2, pp. 215-218, 1985. View at Google Scholar · View at Scopus 